\title{
A cohort analysis of neonatal hospital mortality rate and predictors of neonatal mortality in a sub-urban hospital of Cameroon
}

Paul Koki Ndombo ${ }^{1,2}$, Quinta Mua Ekei ${ }^{3}$, Joel Noutakdie Tochie ${ }^{4,5^{*}}$, Mazou Ngou Temgoua ${ }^{4}$, Francky Teddy Endomba Angong ${ }^{4}$, Ferdinand Ndom Ntock ${ }^{4}$ and Lawrence Mbuagbaw ${ }^{6,7}$

\begin{abstract}
Background: In Cameroon, sustainable effort needs to be done to reduce the current neonatal mortality rate from 21 deaths per 1000 live births to the global target of fewer than ten deaths per 1000 live births by 2035. We aimed to determine the neonatal hospital mortality rate and predictors of neonatal hospital mortality (NHM) in a major referral sub-urban hospital of Cameroon in a bit to formulate interventions to curb this burden.

Methods: This was a prospective cohort study consecutively enrolling all neonates admitted into the neonatology unit of the Bamenda Regional Hospital (BRH) from November 2015 to February 2016. Through interviewed questionnaires to parents and physical examination of neonates, we studied socio-demographic characteristics, antenatal history, intrapartum history and clinical findings of neonates. Neonates further underwent relevant laboratory investigations for diagnosis. All neonates were followed up till 28 days after the post-menstrual term for the neonatal outcomes. Multiple logistic regression was used to determine predictors of NHM.

Results: We enrolled 332 out of 337 neonates admitted to the neonatology unit of BRH during the study period. Fifty-three percent (53\%) were males. Their mean gestational age and birth weight were $36.9 \pm 3.9$ weeks and $2677.2 \pm 923 \mathrm{~g}$, respectively. The main causes of neonatal admissions were complications of preterm birth (32.2\%), neonatal infections (31.3\%), and birth asphyxia (14.5\%). The neonatal hospital mortality rate was $15.7 \%$. NHM was related to complications of preterm birth (69\%), birth asphyxia (23\%) and neonatal infections (6\%). A five-minute Apgar score less than seven was the only predictor of NHM (aOR: 16.41; Cl 95\%: 6.35-42.47; $p<0.01$ ).

Conclusion: Neonatal mortality still remains a significant health problem in sub-urban Cameroon, mainly as a result of three pathologies; complications of preterm birth, birth asphyxia, and infections. There is an urgent need to revamp the current health policies through the improvement of antenatal care, skilled birth attendants, neonatal resuscitation, timely detection and treatment of complications of preterm births, birth asphyxia, and infections.
\end{abstract}

Keywords: Newborns, Hospital neonatal mortality, Predictor, Suburban, Cameroon

\footnotetext{
* Correspondence: joeltochie@gmail.com

${ }^{4}$ Faculty of Medicine and Biomedical Sciences, University of Yaounde 1,

Yaounde, Cameroon

${ }^{5}$ Health and Human development (2HD) Research Group, Douala, Littoral

Region, Cameroon

Full list of author information is available at the end of the article
}

(c) The Author(s). 2017 Open Access This article is distributed under the terms of the Creative Commons Attribution 4.0 International License (http://creativecommons.org/licenses/by/4.0/), which permits unrestricted use, distribution, and reproduction in any medium, provided you give appropriate credit to the original author(s) and the source, provide a link to the Creative Commons license, and indicate if changes were made. The Creative Commons Public Domain Dedication waiver (http://creativecommons.org/publicdomain/zero/1.0/) applies to the data made available in this article, unless otherwise stated. 


\section{Background}

The neonatal period (the first 28 days of life) is a very delicate phase in life due to the risk of acquiring potential life-threatening diseases, and the complexity of the adaptive process of the newborn [1-3]. Global estimates show that 2.8 million neonatal deaths occurred in 2013, accounting for $44 \%$ of deaths in under-fives [4]. There is evidence suggesting a relatively rapid decline in the global under-five mortality compared to the global neonatal mortality (annual rates of reduction $4.9 \%$ vs. $2.9 \%$ ) between the year 2000 and 2013 [4]. With an average neonatal mortality rate (NMR) of 41 per 1000 live births, this burden still remains unresolved in sub-Saharan Africa [5]. This is in contrast with developed countries where there is averagely 4 neonatal deaths per 1000 live births [5]. Consequently, the Every Newborn Action Plan calls for a worldwide reduction in NMR to fewer than ten deaths per 1000 live births by 2035 [6]. The way forward entails designing robust sustainable interventions to prevent and adequately treat complications of preterm birth, birth asphyxia and neonatal sepsis, which jointly account for three-quarter of neonatal deaths globally [4].

Similarly, with 21 neonatal deaths per 1000 live births recorded in Cameroon in 2015, neonatal mortality remains a considerable concern [7]. Previous studies from urban Cameroon cited infections, complications of preterm birth, birth asphyxia, and congenital malformations as the main causes of neonatal hospital mortality [8-10]. Though high birth rates occur in sub-urban Cameroon where access to neonatal health services is inadequate $[11,12]$, epidemiological data on neonatal mortality in this area remains scarce. Furthermore, the patterns of neonatal mortality are useful indicators of the quality of obstetrical and neonatal care in a particular setting, and their assessment ensures the estimation of the quality of health care $[13,14]$. Therefore, we proposed this study to determine the neonatal hospital mortality rate and its predictors in a sub-urban setting of Cameroon. This should inform public health authorities on the current burden of neonatal mortality in order to tailor control interventions to curb this burden.

\section{Methods}

\section{Study area and setting}

This was a hospital-based prospective cohort study carried out from November 11th, 2015 to February 29th, 2016 at the neonatology unit of the Bamenda Regional Hospital (BRH), a secondary level health facility in Cameroon. This hospital situated in the North-West Region of Cameroon serves as a reference health facility for mother and child health care. Its average annual neonatal admission is 900 neonates. The neonatology unit is divided into three sections; a nursery for preterm and low birth weight newborns, a ward for term neonates and a ward for infants aged between two and 3 months. Only neonates admitted to the wards for preterm and low birth weight neonates, and term neonates participated in this study. Infrastructure available in this neonatology unit includes 13 incubators, 45 cots, five phototherapy lamps, two oxygen cylinders and one oxygen extractors, two radiating heat tables, one suctioning machine, two weighing scales, a pulse oximeter, a glucometer, one refrigerator and a gas cooker. The BRH lacks a neonatal intensive care unit. The neonatology unit is taken care of by a paediatrician, two general practitioners, and eight nurses. Nurse to patient ratio varies from 1:12 in the morning shift to 1:25 in the night shift.

\section{Participants and sampling}

We consecutively enrolled all newborns admitted to the neonatology unit during the study period. Newborns whose parents or guardians denied consent were excluded. On admission, we interviewed their parents or guardians, and then examined these newborns. We monitored their outcome till 28 days after post-menstrual term. When a neonate was discharged prior to 28 days after postmenstrual term, weekly home visits and phone calls were used to monitor the newborn's progress at home. The minimal sample size was calculated assuming a 20.3\% [9] hospital neonatal mortality rate and a precision of 5\% [15], hence a minimum of 249 neonates required as study participants.

\section{Data collection, variables and follow-up}

A pre-tested case record form was used to study the following variables;

- Neonatal characteristics: age on admission, gestational age (calculated from last menstrual period), Apgar score at 5th minute, presenting complaint, gender, birth weight, and the findings on physical examination (temperature, heart rate, respiratory rate, neurological state, signs of respiratory distress, abnormal breath sounds, heart murmurs, abdominal distension, enlarged abdominal organs, abdominal masses).

- Maternal characteristics: maternal age, marital status, employment status, place of residence and occupation.

- Obstetrical data: parity, number of antenatal care visits done, prophylaxis during pregnancy, type of pregnancies (multiple or singleton gestation), diseases during pregnancy, mode of delivery (normal vaginal delivery, caesarean section, instrumental delivery), place of delivery, prolonged rupture of membranes, maternal fever, meconium stained amniotic fluid and premature rupture of membranes. 
- Neonatal outcome: duration of hospitalisation, mode of discharge (discharge alive, referred, discharge against medical advice) and death.

\section{Definition of terms}

Neonatal infections were diagnosed based on the presence of infectious risk factors (prolonged rupture of membranes, maternal fever around the delivery period, maternal urogenital infections during the last month of pregnancy, chorioamnionitis, twin with sepsis), clinical signs of infection (fever, hypothermia, pallor, jaundice, refusal to feed, vomiting, abdominal distension, hypotonia, altered consciousness, convulsions, coma) and any of the following biological criteria: leucocytosis $>25,000 /$ $\mathrm{mm}^{3}$, leucopenia $<5000 / \mathrm{mm}^{3}$, platelets $<100,000 / \mathrm{mm}^{3}$, C-reactive proteins $>20 \mathrm{mg} / \mathrm{l}$ [16]. Prematurity was defined based on WHO case definition of a gestational age less than 37 completed weeks [1]. Hypoxic ischaemic encephalopathy (HIE) was diagnosed based on the Modified Sarnat-Sarnat Score [17] and an Apgar score $\leq 3$ at the 5th minute of life associated with neurological signs: hypotonia, coma or convulsions [18]. Bacterial culture and $\mathrm{pH}$ analysis were not used for the diagnosis of neonatal infections and HIE respectively, due to non-availability of the required laboratory apparatus in our health facility at the time of this study. The neonatal hospital mortality rate was defined as the number of deaths occurring among admitted newborns over a given period expressed as a percentage [19].

\section{Data management and statistical analysis}

Data was analysed using SPSS version 20. The threshold of statistical significance set at 0.05 . A bivariate analysis using the Chi-square test or Fisher exact test, where appropriate, was performed to determine predictors of neonatal hospital mortality pertaining to neonatal characteristics (gestational age, birth weight, gender, APGAR score, age on admission, place of delivery, respiratory distress, apnoea, hypothermia, anaemia, hypoglycaemia), maternal characteristics (maternal age, level of education, marital status, employment status, place of residence) and obstetrical characteristics (parity, number of antenatal care visits, hypertensive disorders, HIV/AIDS infection, intrapartum fever, duration of rupture of membranes, nature of amniotic fluid, mode of delivery). Variables with frequencies less than 10 were excluded from statistical analysis. Statistically significant predictors of neonatal hospital mortality were then computed in multiple logistic regression to eliminate confounders. Adjusted odds ratios (aOR) and their corresponding 95\% confidence intervals (95\% CI) were reported. Patients lost to follow-up were excluded from the final analysis.

\section{Ethical considerations}

Ethical authorisations were obtained from the Institutional review Board of the University of Douala, the Regional Delegation of Public Health for the North-West region and from the administrative staff of the Bamenda Regional Hospital prior to the start of the study.

\section{Results}

Out of 337 admissions into the neonatology unit, 332 were enrolled into our study (98.5\% response rate). The five neonates not included in the study were due to refusal of consent by their parents. There was no case lost to follow-up.

\section{Baseline characteristics of neonates}

Among the 332 neonates studied, 53\% were males, $50.9 \%$ were delivered at the BRH and $53.6 \%$ were admitted to the neonatology unit of BRH within the first $24 \mathrm{~h}$ of life. The mean gestational age was $36 \pm 3.9$ weeks (range: 25 to 43 weeks). Their average birth weight was $2677.2 \pm 923 \mathrm{~g}$ (range: Between 600 and $4900 \mathrm{~g}$ ). Neonates with normal birth weight stood at $53.9 \%$. The mean maternal age was $26.4 \pm 5.5$ years. The majority of mothers were unemployed (84.9\%), married (64.8\%) and had at least secondary education (57.8\%). The rest of the general characteristics are reported in Table 1.

\section{Causes of neonatal admissions}

The leading causes of neonatal admissions were complications of preterm birth (32.2\%), neonatal infections (31.3\%) and hypoxic ischaemic encephalopathy (14.5\%) as illustrated in Table 2.

\section{Outcomes of neonatal admissions}

Two hundred and forty-seven newborns (74.3\%) were discharged alive; 52 (15.7\%) newborns died in the course of hospitalization; 30 (9\%) were discharged against medical advice (DAMA) and three (1\%) were referred to a tertiary centre in urban Cameroon for the management of surgical emergencies (two cases of gastroschises and one case of congenital diaphragmatic hernia). The mean duration of hospitalisation in deceased newborns was $2.9 \pm 5.4$ days compared to $15.1 \pm 13$ days in those discharged alive $(p<0.01)$. Out of the 30 newborns DAMA, two died at home from complications of preterm birth (mainly hypothermia) and one died at home from deteriorating sepsis, hence, an overall fatality rate of $16.6 \%$. The causes of neonatal hospital mortality were dominated by complications of prematurity (69\%), HIE (23\%), and neonatal infections (6\%) as shown in Fig. 1. In-hospital deaths from complications of preterm birth (69\%) were as follows; neonatal infections (34\%), respiratory 
Table 1 Baseline characteristics of the newborns and their mothers

\begin{tabular}{|c|c|c|}
\hline Variables & $\begin{array}{l}\text { Number of Newborns } \\
(N=332)\end{array}$ & Frequency (\%) \\
\hline \multicolumn{3}{|l|}{ Gender } \\
\hline Male & 176 & 53 \\
\hline Female & 156 & 47 \\
\hline \multicolumn{3}{|l|}{ Gestational age (weeks) } \\
\hline Preterm $(<37)$ & 111 & 33.4 \\
\hline Term (37-41) & 188 & 56.6 \\
\hline Post term ( $\geq 42)$ & 33 & 9.9 \\
\hline \multicolumn{3}{|l|}{ Age on admission } \\
\hline $0-24 \mathrm{~h}$ & 178 & 53.6 \\
\hline 1-7 days & 103 & 31 \\
\hline $8-28$ days & 51 & 15.5 \\
\hline \multicolumn{3}{|l|}{ Birth weight } \\
\hline Low birth weight (<2500 g) & 132 & 39.8 \\
\hline $\begin{array}{l}\text { Normal birth weight } \\
(2500-3999 \mathrm{~g})\end{array}$ & 179 & 53.9 \\
\hline Macrosomia ( $\geq 4000 \mathrm{~g}$ ) & 21 & 6.3 \\
\hline \multicolumn{3}{|l|}{ Maternal age (years) } \\
\hline$<20$ & 32 & 9.6 \\
\hline $20-34$ & 266 & 80.1 \\
\hline$\geq 35$ & 34 & 10.2 \\
\hline \multicolumn{3}{|l|}{ Marital status } \\
\hline Single & 117 & 35.2 \\
\hline Married & 215 & 64.8 \\
\hline \multicolumn{3}{|l|}{ Educational level } \\
\hline No formal education & 23 & 6.9 \\
\hline Primary & 124 & 37.4 \\
\hline Secondary & 61 & 18.4 \\
\hline Higher & 124 & 37.4 \\
\hline \multicolumn{3}{|l|}{ Employment status } \\
\hline Employed & 50 & 15.1 \\
\hline Unemployed & 282 & 84.9 \\
\hline
\end{tabular}

distress (19\%), HIE (8\%), congenital heart diseases (4\%) and necrotising enterocolitis (4\%).

\section{Predictors of neonatal hospital mortality}

Using bivariate analysis, factors associated with neonatal hospital mortality were low birth weight $(p<0.01)$, prematurity $(p<0.01)$, Apgar score $<7$ at the $5^{\text {th }}$ minute $(p<0.01)$, attending less than four antenatal care visits $(p<0.01)$, residing in a rural area $(p<0.01)$, age on admission $<7$ days $(p<0.05)$, and maternal illnesses $(p<0.05)$ as depicted in Table 3. After multiple logistic regression, an Apgar score less than seven at the 5 th minute was retained as the lone predictor of neonatal hospital mortality (Table 4).
Table 2 Causes of neonatal admissions

\begin{tabular}{|c|c|c|}
\hline Diagnoses & $\begin{array}{l}\text { Number of newborns } \\
N=332\end{array}$ & Frequency (\%) \\
\hline Complications of preterm birth ${ }^{a}$ & 107 & 32.2 \\
\hline Low birth weight & 66 & 19.8 \\
\hline Hypothermia & 43 & 13 \\
\hline Infections & 27 & 8.1 \\
\hline Respiratory distress & 19 & 5.7 \\
\hline Hypoglycaemia & 16 & 4.8 \\
\hline Birth asphyxia & 10 & 3 \\
\hline Jaundice & 08 & 2.4 \\
\hline Congenital heart disease & 02 & 0.6 \\
\hline Necrotizing enterocolitis & 02 & 0.6 \\
\hline Neonatal infections ${ }^{b}$ & 104 & 31.3 \\
\hline Birth asphyxia $^{b}$ & 48 & 14.5 \\
\hline Neonatal jaundice ${ }^{c}$ & 25 & 7.5 \\
\hline Intra-uterine growth restriction & 21 & 6.3 \\
\hline Neonatal respiratory distress & 08 & 2.4 \\
\hline $\begin{array}{l}\text { Transient tachypnoea of the } \\
\text { newborn }\end{array}$ & 06 & 1.8 \\
\hline Meconium aspiration syndrome & 02 & 0.6 \\
\hline Congenital anomalies & 08 & 2.4 \\
\hline Congenital heart disease $^{b}$ & 05 & 1.5 \\
\hline Gastroschisis & 02 & 0.6 \\
\hline $\begin{array}{l}\text { Congenital diaphragmatic } \\
\text { hernia }\end{array}$ & 01 & 0.3 \\
\hline Clinical monitoring & 07 & 2.1 \\
\hline Feeding problems ${ }^{c}$ & 04 & 1.2 \\
\hline Irritability $^{d}$ & 01 & 0.3 \\
\hline $\begin{array}{l}\text { Meconium stained amniotic } \\
\text { fluid }^{d}\end{array}$ & 01 & 0.3 \\
\hline Birth injury & 01 & 0.3 \\
\hline Neonatal seizures ${ }^{d}$ & 02 & 0.6 \\
\hline Hypoglycaemia $^{\text {b }}$ & 02 & 0.6 \\
\hline
\end{tabular}

${ }^{a} 69$ preterm newborns admitted for complications of preterm birth presented with more than one complication

${ }^{\mathrm{b}}$ Excluding cases related to complications of preterm births

${ }^{C}$ Excluding cases related to related to complications of preterm births and neonatal infections

${ }^{d}$ Excluding cases related to neonatal infections and birth asphyxia

\section{Discussion}

This study aimed at determining the neonatal hospital mortality rate and its predictors in a major referral hospital in the North-West region, Cameroon. The three main causes of neonatal admissions were complications of preterm birth, infections and birth asphyxia. The neonatal hospital mortality rate was $15.7 \%$ and mainly related to complications of preterm birth (69\%), birth asphyxia (23\%) and infections (6\%). A five-minute Apgar score less than seven was an independent predictor of 


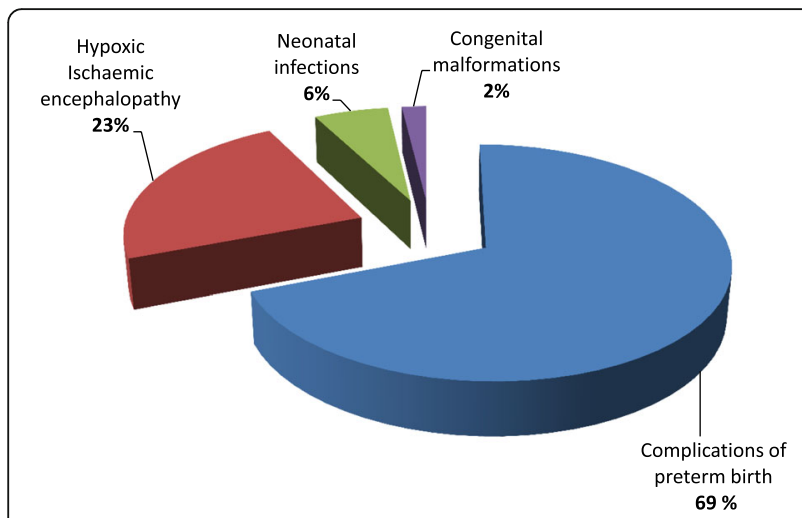

Fig. 1 Causes of neonatal hospital mortality ( $n=52$ neonatal deaths)

neonatal hospital mortality and increased the odds of neonatal hospital mortality by 16 .

In $9 \%$ of cases, the parents or guardians of the neonates systematically requested a DAMA mainly because they could no longer afford the cost of neonatal care. With a daily cost of neonatal care estimated at 10-17 U.S. dollars in our setting, this fee was relatively expensive for an average Cameroonian family, given that $9.6 \%$ of the population live below the international poverty line [20]. Other points in relation to poverty are that $84.9 \%$ of mothers were unemployed and there is no prevailing national health insurance policy for parents who cannot afford health care for their neonates.

The high neonatal hospital mortality rate of $15.7 \%$ could be explained by the referrals of more debilitating cases. Furthermore, among the 52 in-hospital deaths, 43 (83.3\%) occurred during the first week of life which is very critical in the life of a neonate and warrants close follow-up. Our neonatal hospital mortality rate (15.7\%) is superior to the $9.8-10 \%$ reported from urban Cameroon [10, 14, 21], and this can be explained by the inequality of neonatal care between the sub-urban and urban health settings of the country.

Discharged neonates were monitored at home up to 28 days after the post-menstrual term. One neonate DAMA died after 5 days from worsening sepsis while two preterm neonates died from hypothermia after 2 days. As a result, the overall mortality rate shifted from 15.7 to $16.6 \%$. This finding further re-iterates the need for a national health insurance policy, considering the fact that all neonatal deaths from DAMA were compounded by financial constraints which hindered adequate neonatal care.

The causes of neonatal hospital mortality were dominated by complications of preterm birth (69\%), corroborating with contemporary global, regional and national reports [4]. It is projected that complications of preterm birth will probably remain the leading causes of neonatal mortality as well as under-five mortality in 2030 unless full considerations are given to its management $[4,6]$. The preponderance of infections, respiratory distress and birth asphyxia among causes of hospital mortality due to complications of preterm birth in our cohort may be explained by inefficacious antibiotic regimens and possible antibiotic resistance. Other reasons could include suboptimal use of antenatal steroids for preterm labour, lack of specific therapy (exogenous surfactant) for respiratory distress syndrome, the insufficiency of oxygen cylinders and oxygen extractors for supportive treatment of respiratory distress, unskilled birth attendants and defective neonatal resuscitation practices for preterm neonates with birth asphyxia. Meanwhile, no fatal outcome was observed in complications of preterm births like hypothermia and hypoglycaemia. This may imply satisfactory means of thermoregulation by incubators and kangaroo mother care for preterm newborns with hyporthermia, effective glucose therapy and breastfeeding practices to control hypoglycaemia in this setting. In contrast, studies from urban Cameroon [9, 21-23] observed a higher proportion of neonatal infection-related deaths (37.5-60\%) compared to the of 6\% recorded in our study. This could be explained by the recent refresher courses on the hygienic care of childbirth and the postnatal period undertaken by the obstetrical and neonatal staff of our hospital.

An Apgar score less than seven at the 5th minute was an independent predictor of neonatal hospital mortality, concurring with Ekure et al. in Nigeria [24] and Chiabi et al. in urban Cameroon [21]. Noteworthy, this score is often criticized for being subjective $[25,26]$ and prone to errors in the assessment of neonatal adaptation of preterm neonates, in whom the muscle tone, colour and reflexes partially depend on the physiological maturity of the newborn [27]. However, until a simpler and more useful clinical scoring system for assessing neonates is developed, our finding suggests that an Apgar score less than seven at the 5th minute is associated with inefficient neonatal resuscitation and therefore neonatal mortality.

The main limitation of our study is that it is a singlecentre study, though, the findings obtained can still be generalised because they portray similar aetiologies of neonatal hospital mortality observed in urban settings of Cameroon $[9,10,21]$ and abroad $[28,29]$. The merits of this study include its prospective cohort design and robust statistical methods to provide a contribution of level II scientific evidence [30] to the scarcity of data on neonatal hospital mortality in a sub-urban tropical setting. Other similar studies [14, 23, 31, 32] have been conducted in urban Cameroon using a retrospective design, thus there is a risk that some of the records studied were not correctly filled with resultant inaccurate results on neonatal hospital mortality. 
Table 3 Predictors of neonatal hospital mortality at a bivariate analysis

\begin{tabular}{|c|c|c|c|c|c|}
\hline Variable & $\begin{array}{l}\text { Dead } \\
\text { newborns }(n=52)\end{array}$ & Newborns discharged alive $(n=280)$ & Odds ratio & 95\% confidence interval & $p$-value \\
\hline \multicolumn{6}{|l|}{ Neonatal characteristics } \\
\hline \multicolumn{6}{|l|}{ Gestational age } \\
\hline$<37$ weeks & $34(65 \%)$ & $77(28 \%)$ & 4.98 & $2.66-9.34$ & $<0.01$ \\
\hline$\geq 37$ weeks & $18(35 \%)$ & $203(72 \%)$ & & & \\
\hline \multicolumn{6}{|l|}{ Birth weight (grams) } \\
\hline$<2500$ & $37(71 \%)$ & $95(34 \%)$ & 4.80 & $2.51-9.19$ & $<0.01$ \\
\hline$\geq 2500$ & $15(29 \%)$ & $185(66 \%)$ & & & \\
\hline \multicolumn{6}{|l|}{ Gender } \\
\hline Male & $30(58 \%)$ & $146(52 \%)$ & 1.25 & $0.69-2.28$ & 0.4621 \\
\hline Female & $22(42 \%)$ & $134(48 \%)$ & & & \\
\hline \multicolumn{6}{|l|}{ APGAR at 5 th minute } \\
\hline$<7$ & $44(85 \%)$ & $64(23 \%)$ & 18.56 & $8.31-41.45$ & $<0.01$ \\
\hline$\geq 7$ & $8(15 \%)$ & $216(77 \%)$ & & & \\
\hline \multicolumn{6}{|l|}{ Age on admission (days) } \\
\hline $0-7$ & 49 (94\%) & $232(83 \%)$ & 3.38 & $1.01-11.29$ & $<0.05$ \\
\hline $7-28$ & $3(6 \%)$ & $48(17 \%)$ & & & \\
\hline \multicolumn{6}{|l|}{ Place of birth } \\
\hline $\mathrm{BRH}$ & $21(40 \%)$ & $148(53 \%)$ & 0.60 & $0.33-1.10$ & 0.1007 \\
\hline Others & $31(60 \%)$ & $132(47 \%)$ & & & \\
\hline \multicolumn{6}{|l|}{ Maternal characteristics } \\
\hline \multicolumn{6}{|l|}{ Maternal age (years) } \\
\hline$<20$ and $\geq 35$ & $13(25 \%)$ & $53(19 \%)$ & 1.43 & $0.71-2.86$ & 0.3155 \\
\hline $20-34$ & $39(75 \%)$ & $227(81 \%)$ & & & \\
\hline \multicolumn{6}{|l|}{ Level of education } \\
\hline Primary or less & $27(52 \%)$ & $120(43 \%)$ & 1.44 & $0.79-2.61$ & 0.2283 \\
\hline Secondary or more & $25(48 \%)$ & $160(57 \%)$ & & & \\
\hline \multicolumn{6}{|l|}{ Marital status } \\
\hline Single & $23(44 \%)$ & $94(34 \%)$ & 1.57 & $0.86-2.86$ & 0.1415 \\
\hline Married & $29(56 \%)$ & $186(66 \%)$ & & & \\
\hline \multicolumn{6}{|l|}{ Occupational status } \\
\hline Unemployed ${ }^{a}$ & $44(85 \%)$ & $238(85 \%)$ & 0.97 & $0.43-2.21$ & 0.9432 \\
\hline Employed & $8(15 \%)$ & $42(15 \%)$ & & & \\
\hline \multicolumn{6}{|l|}{ Place of residence } \\
\hline Rural area & $20(38 \%)$ & $47(17 \%)$ & 3.09 & $1.63-5.88$ & $<0.01$ \\
\hline Sub-urban area & $32(62 \%)$ & $233(83 \%)$ & & & \\
\hline \multicolumn{6}{|l|}{ Obstetrical characteristics } \\
\hline \multicolumn{6}{|l|}{ Parity } \\
\hline Primiparity and Grand Multiparity & $33(63 \%)$ & $137(49 \%)$ & 1.81 & $0.98-3.34$ & 0.0564 \\
\hline Multiparity & 19 (37\%) & $143(51 \%)$ & & & \\
\hline \multicolumn{6}{|l|}{ Number of antenatal visits } \\
\hline $0-3$ & $30(58 \%)$ & $86(31 \%)$ & 3.08 & $1.68-5.64$ & $<0.01$ \\
\hline$\geq 4$ & $22(42 \%)$ & $194(69 \%)$ & & & \\
\hline
\end{tabular}


Table 3 Predictors of neonatal hospital mortality at a bivariate analysis (Continued)

\begin{tabular}{|c|c|c|c|c|c|}
\hline \multicolumn{6}{|c|}{ Maternal illnesses during pregnancy } \\
\hline Yes & $22(42 \%)$ & $73(26 \%)$ & 2.08 & $1.13-3.83$ & $<0.05$ \\
\hline No & $30(58 \%)$ & $207(74 \%)$ & & & \\
\hline \multicolumn{6}{|c|}{ Maternal fever during labour } \\
\hline Yes & $1(2 \%)$ & $16(6 \%)$ & 0.32 & $0.04-2.49$ & 0.2788 \\
\hline No & $51(98 \%)$ & $264(94 \%)$ & & & \\
\hline \multicolumn{6}{|c|}{ Duration of rupture of membranes(hours) } \\
\hline$\geq 12$ & $18(35 \%)$ & $64(23 \%)$ & 1.79 & $0.95-3.37$ & 0.0736 \\
\hline$<12$ & $34(65 \%)$ & $216(77 \%)$ & & & \\
\hline \multicolumn{6}{|c|}{ Meconium stained liquor } \\
\hline Yes & $4(8 \%)$ & $12(4 \%)$ & 1.86 & $0.58-6.01$ & 0.2991 \\
\hline No & $48(92 \%)$ & $268(96 \%)$ & & & \\
\hline \multicolumn{6}{|l|}{ Mode of delivery } \\
\hline Vaginal & $46(89 \%)$ & $221(79 \%)$ & 2.05 & $0.83-5.02$ & 0.1179 \\
\hline Caesarean section & $6(11 \%)$ & $59(21 \%)$ & & & \\
\hline
\end{tabular}

BRH Bamenda Regional Hospital

${ }^{\mathrm{a}}$ Housewives, students

\section{Conclusion}

This is one of the first studies investigating neonatal hospital mortality in a major referral hospital in a suburban Cameroon. Its findings suggest that neonatal hospital mortality is still high and accounted by three main pathologies; complications of preterm births, birth asphyxia and neonatal sepsis. Substantial efforts to improve antenatal care, antenatal steroids for preterm labour, sound feeding practices, and early identification and treatment of preterm birth complications could help reduce the burden of neonatal hospital mortality in preterm neonates. Skilled birth attendants and improved neonatal resuscitation schemes may curb the incidence and mortality related to birth asphyxia. Meanwhile, timely detection and treatment of maternal infections, and the use of hygienic childbirth practices may be invaluable in

Table 4 Predictors of neonatal hospital mortality at logistic regression

\begin{tabular}{llll}
\hline Variable & $\begin{array}{l}\text { Adjusted odds } \\
\text { ratio }\end{array}$ & $\begin{array}{l}\text { 95\% confidence } \\
\text { interval }\end{array}$ & $p$-value \\
\hline $\begin{array}{l}\text { Age on admission } \\
\text { 0-7 days }\end{array}$ & 1.77 & $0.31-10.25$ & 0.527 \\
$\begin{array}{l}\text { Birth weight }<2500 \mathrm{~g} \\
\begin{array}{l}\text { Apgar score }<7 \text { at } \\
\text { 5th minute }\end{array}\end{array}$ & 7.41 & $0.48-115.31$ & 0.152 \\
$\begin{array}{l}\text { Gestationalage }<37 \text { weeks } \\
\text { Number of antenatal }\end{array}$ & 0.73 & $6.35-42.47$ & $<0.01$ \\
$\begin{array}{l}\text { visits }<4 \\
\text { Maternal illnesses during } \\
\text { pregnancy }\end{array}$ & 1.66 & $0.32-1.68$ & 0.458 \\
\begin{tabular}{l} 
Residence in rural area \\
\hline
\end{tabular} & 0.55 & $0.51-3.54$ & 0.557 \\
\hline
\end{tabular}

tackling neonatal infections. Also, there should be a reinforcement of refresher courses for health care providers on the management of neonatal infections, birth asphyxia and complications of preterm births. Lastly, a national health insurance policy could be instituted in order to render health care accessible to this vulnerable population. Cost-benefits studies are warranted for this regards. Overall, these policies will go a long way to build sustainable health care systems that could help reduce the neonatal hospital mortality rate in sub-urban Cameroon by 2035 .

\section{Abbreviations}

BRH: Bamenda Regional Hospital; DAMA: Discharged Against Medical Advice; HIE: Hypoxic Ischaemic Encephalopathy; NMR: Neonatal Mortality Rate; WHO: World Health Organisation

\section{Acknowledgments}

We would like to thank the entire staff of the neonatology unit of the Bamenda Regional Hospital for taking part in the care of the newborns included in this study. The authors are indebted to Dr. Veronica Aletum for proofreading this study.

\section{Funding}

None.

Availability of data and materials

All data generated or analysed during this study are included in this published study.

\section{Authors' contributions}

PNK, JNT and LM: Study conception and design, acquisition of data, data analysis and interpretation, manuscript writing and critical revisions. QME: Study conception and design, acquisition of data, data analysis and interpretation and manuscript writing. MNT, FTEA, and FNN: Acquisition of data, data analysis and interpretation and critical revisions. All authors read and approved the final manuscript. 


\section{Competing interests}

The authors declare that they have no competing interests.

\section{Consent for publication}

Written informed consent was obtained from the parents or guardians of newborns for publication of this study.

\section{Ethics approval and consent to participate}

An ethical clearance was obtained from the Institutional review Board of the University of Douala prior to the start of the study under No IEC-UD/467/02/ $2016 / T$. Administrative authorizations were equally obtained from the Regional Delegation of Public Health for the North-West Region and from the administration of the Bamenda Regional Hospital.

\section{Publisher's Note}

Springer Nature remains neutral with regard to jurisdictional claims in published maps and institutional affiliations.

\section{Author details \\ 'Mother and Child Center, Chantal Biya Foundation, Yaounde, Cameroon. ${ }^{2}$ Department of Paediatrics, Faculty of Medicine and Biomedical Sciences, University of Yaounde 1, Yaounde, Cameroon. ${ }^{3}$ Faculty of Health Sciences, University of Buea, Buea, Cameroon. ${ }^{4}$ Faculty of Medicine and Biomedical Sciences, University of Yaounde 1, Yaounde, Cameroon. ${ }^{5}$ Health and Human development (2HD) Research Group, Douala, Littoral Region, Cameroon. ${ }^{6}$ Department of Pediatrics, Buea Regional Hospital, Buea, Cameroon. ${ }^{7}$ Department of Pediatrics, Faculty of Health Sciences, University of Buea, Buea, Cameroon.}

Received: 27 February 2017 Accepted: 29 May 2017 Published online: 05 June 2017

\section{References}

1. Lawn JE, Davidge R, Paul VK, von Xylander S, de Graft Johnson J, Costello A, et al. Born too soon: care for the preterm baby. Reprod Health. 2013; 10(Suppl 1):S5

2. Rahim F, Jan A, Mohummad J, labal H. Pattern and outcome of admissions to neonatal unit of Khyber teaching hospital, Peshawar. Pakistan J Med Sci. 2007;23(2):249-53.

3. UNICEF, WHO, The World Bank, UN. Levels and trends in child mortality: report 2012. Estimates developed by the UN inter-agency Group for Child Mortality Estimation. New York: UNICEF Headquaters; 2012. p. 2.

4. Liu L, Oza S, Hogan D, Perin J, Rudan I, Lawn JE, et al. Global, regional, and national causes of child mortality in 2000-13, with projections to inform post-2015 priorities: an updated systematic analysis. Lancet. 2015:385(9966):430-40

5. Lawn JE, Kerber K, Enweronu-Laryea C, Cousens S. 3.6 million neonatal deaths-what is progressing and what is not? Semin Perinatol. 2010; 34(6):371-86

6. Lawn J, Blencowe H, Oza S, You D, Lee A, Waiswa P, et al. Every newborn: progress, priorities, and potential beyond survival. Lancet. 2014;384(9938):189-25.

7. UNICEF, WHO, World BANK GROUP, UN. Levels and trends in child mortality: report 2015. Estimates developed by the UN inter-agency Group for Child Mortality Estimation. New York: UNICEF Headquaters; 2015. p. 19.

8. UNICEF. The state of the world's children 2009: maternal and newborn health. New York: UNICEF, Division of Communication; 2008. p. 57.

9. Kedy DC, Essomba NE, Ngaba GP, Sintat S, Ndombo PK, Coppieters Y. Morbidité et facteurs de risque de mortalité néonatale dans un hôpital de référence de Douala. Pan Afr Med J. 2015;20:258.

10. Kedy Koum D, Exhenry C, Penda C-I, Nzima Nzima V, Pfister RE. Morbidité et mortalité néonatale dans un hôpital de district urbain à ressources limitées à Douala. Cameroun Arch Pédiatrie. 2014;21(2):147-56.

11. Choukem S-P, Njim T, Atashili J, Hamilton-Shield JP, Mbu R. High birth weight in a suburban hospital in Cameroon: an analysis of the clinical cut-off, prevalence, predictors and adverse outcomes. BMJ Open. 2016; 6(6):e011517.

12. Njim T, Atashili J, Mbu R, Choukem S-P. Low birth weight in a sub-urban area of Cameroon: an analysis of the clinical cut-off, incidence, predictors and complications. BMC Pregnancy Childbirth. 2015;15(1):288.
13. Nwosu J, Odubanjo MO, Osinusi BO, editors. The Nigerian Academy of science: reducing maternal and infant mortality in Nigeria (workshop summary). Lagos: West African Book Publishers; 2009. p. 14-117.

14. Mah M, Chiabi A, Tchokoteu P, Nguefack S, Bogne J, Siyou H, et al. Neonatal mortality in a referral hospital in Cameroon over a seven year period: trends, associated factors and causes. Afr Health Sci. 2014;14(3):517-25.

15. Eng J. Sample size estimation: how many individuals should be studied? Radiology. 2003;227(2):309-13.

16. Agence Nationale d'Accréditation et d'Evaluation en Sante. Diagnostic et Traitement Curatif de I'Infection Bactérienne Précoce du Nouveau-né. Paris: ANAES, Service Communication et Diffusion; 2002.

17. Sarnat HB, Sarnat MS. Neonatal encephalopathy following fetal distress. A clinical and electroencephalographic study. Arch Neurol. 1976;33(10):696-705.

18. American Academy of Pediatrics and American College of Obstetricains and Gynecologists. Care of the neonate. In: Gilstrap LC, Oh W, editors. Guidelines for perinatal care. 5th ed. Elk Grove Village (IL): American Academy of Pediatrics; 2002. p. 196-7.

19. WHO. Perinatal mortality: a listing of available information. Geneva: WH, Family and Reproductive Health; 1996. p. 1-4.

20. WHO. World Health Statistics. 2012. p. 159. Available from http://apps.who. int/iris/bitstream/10665/44844/1/9789241564441_eng.pdf. Accessed 20 Mar 2017

21. Chiabi A, Takou V, Mah E, Nguefack S, Siyou H, Takou V, et al. Risk factors for neonatal mortality at the Yaounde Gynaeco-obstetric and pediatric hospital, Cameroon. Iran J Pediatr. 2014;24(4):393-400.

22. Tochie JN, Choukem S-P, Langmia RN, Barla E, Koki-Ndombo P. Neonatal respiratory distress in a reference neonatal unit in Cameroon: an analysis of prevalence, predictors, etiologies and outcomes. Pan Afr Med J. 2016;24:152.

23. Tietche F, Kago I, Njimoke A, Mbonda E, Ndombo PK, Tetanye E. Mortalité hospitalière des nouveau-nés eutrophiques à terme à Yaoundé (Cameroun): Aspects étiologiques. Médecine Afr Noir. 1998:45(3):193-5.

24. Ekure EN, Ezeaka VC, Iroha E, Egri-Okwaji M. Prospective audit of perinatal mortality among inborn babies in a tertiary health center in Lagos, Nigeria. Niger J Clin Pract. 2011;14(1):88-94

25. Manganaro R, Mamì C, Gemelli M. The validity of the Apgar scores in the assessment of asphyxia at birth. Eur J Obstet Gynecol Reprod Biol. 1994:54(2):99-102.

26. Kolatat T, Vanprapar N, Thitadilok W. Perinatal asphyxia: multivariate analysis of risk factors. J Med Assoc Thail Chotmaihet Thangphaet. 2000;83(9):1039-44.

27. Use and abuse of the Apgar score. Committee on Fetus and Newborn, American Academy of Pediatrics, and Committee on Obstetric Practice, American College of Obstetricians and Gynecologists. Pediatrics. 1996:98(1):141-2.

28. Ekure EN, Ezeaka VC, Iroha EO, Egri-Okwaji MTC. Neonatal mortality of in-borns in the neonatal unit of a tertiary centre in Lagos, Nigeria. Niger Q J Hosp Med. 2005;15(2):55-8.

29. Djadou K-E, Azouma D, Yable G, Dakey G, Sanda P, Dokounor D, et al. Mortalité néonatale au centre hospitalier régional de Tsévié (Togo). Arch Pédiatrie. 2006;13(8):1156.

30. Haute Autorité de Santé. Niveau de preuve et gradation des recommandations de bonne pratique - État des lieux. Paris: HAS, Service documentation - information des publics; 2013. p. 8.

31. Monebenimp F, Tchiro R, Nana AD. Morbidité et mortalité des naissances intra-hospitalières du Centre Hospitalier Universitaire de Yaoundé Cameroun. Clin Mother Child Heath. 2005:2:355-8.

32. Chelo D, Monebenimp F, Tedongmeza Npanguepko FR, Tietche F. Mortalité néonatale précoce et ses déterminants dans une maternité de niveau I à Yaoundé, Cameroun. Pan Afr Med J. 2012;13:67. 